\title{
Vitamin-Mineral Supplement Use Patterns in Elderly Koreans: Data from the 2007-2008 Korean National Health and Nutrition Examination Survey
}

\author{
So Young Park', Yun Jin Kim ${ }^{1,2, *}$, Sang Yeoup Lee ${ }^{2,3,4}$, Jeong Gyu Lee ${ }^{1,2}$, Hye Rim Hwang ${ }^{1,2}$, Dong Wook Jeong ${ }^{2,3}$, \\ Young Hye Cho ${ }^{2,3}$, Eun Jung $\mathrm{Choi}^{2,3}$, Yu Hyeon $\mathrm{Yi}^{1,2}$, Young Jin $\mathrm{Tak}^{1,2}, \mathrm{~A}$ Ra Jo ${ }^{2,3}$, Seung Hoon Lee ${ }^{1,2}$, \\ Jeong Suk Jeon ${ }^{2,3}$, Bo Wha Lee \\ 'Department of Family Medicine, Pusan National University Hospital, Busan, Korea \\ ${ }^{2}$ Department of Family Medicine, Pusan National University School of Medicine, Busan, Korea \\ ${ }^{3}$ Department of Family Medicine, Pusan National University Yangsan Hospital, Yangsan, Korea \\ ${ }^{4}$ Medical Education Unit and Medical Research Institute, Pusan National University School of Medicine, Yangsan, Korea
}

Background: Vitamin-mineral supplements are the most popular dietary supplements in Korea. However, few studies have assessed the relationship between vitamin-mineral supplementation and associated factors among the Korean elderly. The purpose of this study was to assess the use of vitamin-mineral supplements among elderly in Korea as well as its association with sociodemographic factors, health-related behaviors, medical conditions, and nutrient intake.

Methods: This study was based on data from the Korean National Health and Nutrition Examination Survey, conducted by the Korean Ministry of Health and Welfare from 2008 to 2009. Data from 3,294 elderly men and women (65 years of age and older) were analyzed. Multivariable-weighted logistic regression model analysis was used to evaluate the association between vitamin-mineral supplement use and sociodemographic factors, health-related habits, and medical conditions.

Results: Vitamin-mineral supplementation was reported by $16.3 \%$ of the participants. The most common reason for using dietary supplements was recommendations from friends and acquaintances. Highly educated person, female participants had a greater likelihood of taking vitamin-mineral supplements. In addition, analysis of nutrient intake from food sources alone revealed a lower proportion of vitamin-mineral supplement users with nutrient intakes below the estimated average requirements for vitamin A, vitamin C, thiamine, riboflavin, niacin, calcium, iron, and phosphorus, compared to nonusers. However, vitamin-mineral supplementation was not associated with health-related behaviors or medical conditions.

Conclusion: Highly educated person, elderly Korean women had a greater likelihood of using vitamin-mineral supplements. In addition, nutrient intakes from food sources alone were significantly higher among vitamin-mineral supplement users. Finally, vitamin-mineral supplementation may be an indicator of healthier diet in elderly Koreans.

Keywords: Elderly; Dietary Supplement; Vitamins; Nutrition; Koreans 


\section{INTRODUCTION}

Vitamin-mineral supplements are the most popular dietary supplement in Korea. According to the fourth Korean National Health and Nutrition Examination Survey (KNHANES), approximately $16 \%$ of men and $26 \%$ of women aged 19 years and over reported using vitamin-mineral supplements. ${ }^{1)}$ Vitamin-mineral supplements are also the most common dietary supplements in the United States and $\mathrm{Eu}-$ rope. $^{2-4)}$

The results of a previous cohort study revealed that vitamin-mineral supplementation reduced the risk of myocardial infarction by $30 \%$, and longer duration of supplementation was associated with further reduced risk. ${ }^{5)}$ Another meta-analysis reported that intake of vitamin supplements including the antioxidants vitamins $\mathrm{C}$ and $\mathrm{E}$ reduced glycated hemoglobin (A1c) levels. ${ }^{6}$ In addition, daily vitamin-mineral supplementation prevented colorectal cancer and was associated with a reduction in total cancer, especially in men. ${ }^{7,8)}$

With increasing evidence of the effect of vitamin-mineral supplementation on disease prevention and cure, studies on the prevalence of supplement use and factors related to their use are also increasing. Previous research has indicated that older age, ${ }^{4,9,10)}$ female sex, ${ }^{11-13)}$ higher educational level, ${ }^{4,11,12)}$ lower body mass index, ${ }^{10)}$ higher economic status, ${ }^{10,13,14)}$ physical activity, ${ }^{9,11)}$ and healthier $\operatorname{diet}^{9-12,14)}$ are associated with increased use of vitamin-mineral supplements.

Many studies in Korea have assessed the prevalence of supplement use and characteristics in Korean children, adolescents, and adults, ${ }^{10,12,14)}$ but research in the elderly has mainly focused on the nutritional aspects, and there has been no nationally representative survey. ${ }^{13)}$ Therefore, the purpose of this study was to describe the use of vitamin-mineral supplements among elderly Koreans, along with the sociodemographic factors, health-related behaviors, medical conditions, and nutrient intake associated with its use.

\section{METHODS}

\section{Study Participants}

This study was based on the fourth KNHANES conducted by the Korea Centers for Disease Control and Prevention. From 2008 to 2009, a total of 8,000 households and 20,277 people were enrolled. Data from 3,294 elderly men and women (above 65 years of age) were analyzed, with no exclusions.

\section{Study Method}

The KNHANES, ${ }^{15)}$ a nationwide study, examined the general health and nutritional status of Koreans. Participants were selected based on data from the Population and Housing Census. The fourth KNHANES included all individuals and households in the 2005 Population and Housing Census.

The KNHANES database is divided into three categories: health interview survey, nutritional survey, and health examination survey. The health interview and examination surveys were conducted in mobile examination units by individual interviewers. The nutritional survey included questions regarding diet behavior, dietary supplement intake, and nutritional knowledge. Food and nutrient intakes were assessed using self-reported data obtained from a one-day (24-hour) recall of the day prior to administration of the survey.

\section{1) Sociodemographic factors}

The health interview survey collected data regarding participant age, sex, residential area, educational level, and household income, physical activity, cigarette smoking, alcohol drinking, and tea drinking.

\section{2) Health behaviors and general medical comorbidities}

Body mass index was calculated from measured height and weight (kilograms/meters squared). Abdominal obesity was defined the measured waist circumferences $\geq 90 \mathrm{~cm}$ in men or $\geq 85 \mathrm{~cm}$ in women. ${ }^{16}$ Medical conditions, including dyslipidemia, diabetes mellitus (DM), cerebrovascular disease (CVD), coronary heart disease (CHD), hypertension, osteoporosis, and cancer (gastric, liver, breast, lung, or cervical), were assessed by interview. In addition, participants with measured blood pressures $\geq 140 / 90 \mathrm{~mm}$ Hg were classified as hypertensive; those with measured hemoglobin Alc levels $\geq 6.5 \%$ were classified as having DM; and total cholesterol $\geq 240 \mathrm{mg} / \mathrm{dL}$, high density lipoprotein cholesterol $<40 \mathrm{mg} / \mathrm{dL}$, and triglyceride levels $\geq 200 \mathrm{mg} / \mathrm{dL}$ were suggestive of dyslipidemia; in addition, participants previously clinically diagnosed with these conditions were classified as having these diseases.

\section{3) Health behaviors}

Regular diet behavior was assessed by asking participants if they had skipped any meals during the previous one and two days. Self-reported health statuses were classified as 'good,' 'moderate,' or 'bad.' Regular health check-ups and influenza vaccinations were also assessed.

\section{4) Vitamin-mineral supplement use}

Vitamin-mineral supplement users were defined as participants who replied "Yes" to the question, "Do you take a vitamin-mineral supplement?" The reasons, categories, duration, and frequency of vitaminmineral and other dietary supplement use were also assessed.

\section{5) Nutrient intake from food sources}

The analysis of nutrient intake from food alone included eight nutrients: vitamin A, vitamin C, thiamine, riboflavin, niacin, calcium, iron, and phosphorus. The percentages of participants with nutrient intakes below the estimated average requirement (EAR) were calculated. Food and nutrient intakes were assessed by the one-day, 24-hour recall method.

\section{Statistical Analysis}

KNHANES offers multistage, stratified, and complex survey sampling data; complex sample design analysis was used in the current study. Sampling weight was calculated based on the number of sampled 
units, according to KNHANES guidelines.

The reasons, categories, duration, and frequency of vitamin-mineral and other dietary supplementation were calculated by frequency analysis. Odds ratios (ORs) and 95\% confidence intervals (CIs) were calculated using a multivariable-weighted logistic regression model to evaluate the association between vitamin-mineral use and demographic factors, lifestyle characteristics and health behaviors, and medical conditions. Multivariable-weighted logistic regression was also used to compare the ratio of participants with nutrient intake from food alone below the EAR between vitamin-mineral user and nonuser. All statistical analyses were performed using SAS ver. 9.3 (SAS Institute Inc., Cary, NC, USA) or PASW SPSS Statistics for Windows ver. 18.0 (SPSS Inc., Chicago, IL, USA), with a level of significance of $\mathrm{P}<0.05$.

\section{RESULTS}

Among 3,294 elderly aged 65 years and above, 537 (16.3\%) reported using vitamin-mineral supplements. The mean participant age was 72 years and $40.6 \%$ were men.

\section{Reason, Category, Duration, and Frequency of Dietary Supplement Use}

The most common reason for dietary supplement use was recommendation from friends and acquaintances (72.8\%). The elderly in Korea prefer functional foods (56.3\%) to vitamin-mineral supplements (42.1\%). The mean duration of supplement use was about 17 months, and most reported taking supplements once per day (60\%) (Table 1).

Table 1. Reason, category, duration, and frequency of dietary supplement use

\begin{tabular}{lr}
\multicolumn{1}{c}{ Variable } & Value \\
\hline Reason for supplementation & \\
Doctor recommendation & $4.3(0.8)$ \\
Pharmacist recommendation & $2.1(0.5)$ \\
Friend or acquaintance recommendation & $72.8(1.8)$ \\
Own judgment & $19.1(1.5)$ \\
Advertisement & $0.7(0.4)$ \\
Other & $1.1(0.5)$ \\
Supplement types & \\
Vitamin/mineral/multi-vitamin & $42.1(2.2)$ \\
Food supplements & $56.3(2.1)$ \\
Other & $1.6(0.5)$ \\
Average duration of supplement use (mo) & $16.97 \pm 1.44$ \\
Frequency of supplement use & \\
$\geq 3$ times daily & $4.5(0.9)$ \\
2 times daily & $27.0(2.0)$ \\
1 time daily & $60.0(2.1)$ \\
$2-5$ times weekly & $7.2(1.1)$ \\
$\leq 1$ time weekly & $1.3(0.5)$ \\
\hline
\end{tabular}

Values are presented as \% (standard error) or mean \pm standard error.

\section{Demographic and Lifestyle Characteristics, and Health Behaviors among Vitamin-Mineral Supplement Users}

Before adjusting for demographic, lifestyle characteristics, and health behaviors, vitamin-mineral supplementation was associated with higher household income (OR, 2.0; 95\% CI, 1.3-3.3), city living (OR, 0.6; 95\% CI, 0.5-0.8), higher education level (OR, 3.9; 95\% CI, 2.5-6.3), nonsmoking (OR, 1.5; 95\% CI, 1.1-2.2), and drinking tea more than once a week (OR, 1.7; 95\% CI, 1.3-2.3). However, after adjustment, the likelihood of vitamin-mineral supplement use was greater if participants were female (adjusted OR, 2.0; 95\% CI, 1.3-2.9), and with a higher education level (adjusted OR, 4.3; 95\% CI, 2.6-7.1); there was no association between supplement use and other demographic and lifestyle characteristics. In addition, health behaviors such as regular diet, selfreported health status, regular health check-ups and influenza vaccination were not related to use of vitamin-mineral supplements (Table 2).

\section{Medical Condition among Vitamin-Mineral Supplement Users}

There was no significant difference between vitamin-mineral supplement use and the incidence of hypertension, DM, dyslipidemia, CVD, CHD, osteoporosis, cancer, and abdominal obesity (Table 3).

\section{Nutrient Intakes from Food Alone (Except for Supplements) among Vitamin-Mineral Supplement Users}

Table 4 summarizes nutrient intakes from food alone among vitaminmineral supplement users and nonusers. The proportions of participants with nutrient intakes below the EAR were calculated for men and women separately. Food and nutrient intakes were assessed using the one-day, 24-hour recall method. Analysis of nutrient intake from food sources alone revealed a lower proportion of participants with vitamin A, vitamin C, thiamine, riboflavin, niacin, calcium, iron, and phosphorus nutrient intakes below the EAR among vitamin-mineral supplement user than among nonusers.

\section{DISCUSSION}

We investigated the prevalence of vitamin-mineral supplement use and the characteristics of these users among Korean elderly. In current study, about $16.3 \%$ of elderly Koreans reported using vitamin-mineral supplements. The most common reason for their use was recommendation from friends and acquaintances, (73\%), compared to doctor recommendation, at only $4.3 \%$. This result suggests that participants didn't get Information about dietary supplement from health professionals. Therefore, health professionals should inquire about supplement use and provide patients with specific information.

Before adjusting for sociodemographic factors and health-related higher household income behaviors, vitamin-mineral supplement use was associated with city living, higher education level, nonsmoking, and drinking tea more than once a week. After adjusting, highly educated person, female participants had a greater likelihood of using vitamin-mineral supplements. 
Table 2. Demographic and lifestyle characteristics and health behaviors among participants taking vitamin-mineral supplements

\begin{tabular}{|c|c|c|c|c|}
\hline \multirow{2}{*}{ Characteristic } & \multicolumn{2}{|c|}{$\%$ (Standard error) } & \multicolumn{2}{|c|}{ 95\% confidence interval } \\
\hline & Vitamin-mineral nonuser & Vitamin-mineral user & Unadjusted odds ratio* & Adjusted $^{\dagger}$ odds ratio* \\
\hline \multicolumn{5}{|l|}{ Sex } \\
\hline Male & $83.1(1.6)$ & $16.9(1.6)$ & 1 & 1 \\
\hline Female & $79.9(1.3)$ & $20.1(1.3)$ & $1.2(1.0-1.5)$ & $2.0(1.3-2.9)$ \\
\hline \multicolumn{5}{|l|}{ Age $(y)$} \\
\hline $65-74$ & $79.8(1.3)$ & $20.2(1.3)$ & 1 & 1 \\
\hline$\geq 75$ & $83.8(1.6)$ & $16.2(1.6)$ & $0.8(0.6-1.0)$ & $0.8(0.6-1.1)$ \\
\hline \multicolumn{5}{|l|}{ Residential area } \\
\hline City & $79.2(1.5)$ & $20.8(1.5)$ & 1 & 1 \\
\hline Rural area & $85.6(1.4)$ & $14.4(1.4)$ & $0.6(0.5-0.8)$ & $0.8(0.6-1.1)$ \\
\hline \multicolumn{5}{|l|}{ Educational level $^{\ddagger}$} \\
\hline Low & $83.5(1.1)$ & $16.5(1.1)$ & 1 & 1 \\
\hline Middle & $77.1(3.2)$ & $22.9(3.2)$ & $1.5(1.0-2.2)$ & $1.6(1.1-2.4)$ \\
\hline High & $56.2(5.8)$ & $43.8(5.8)$ & $3.9(2.5-6.3)$ & $4.3(2.6-7.1)$ \\
\hline \multicolumn{5}{|l|}{ Marital status } \\
\hline Living with life partner & $81(1.5)$ & $19.0(1.5)$ & 1 & 1 \\
\hline Living alone & $81.1(1.5)$ & $18.9(1.5)$ & $1.0(0.8-1.3)$ & $1.1(0.8-1.4)$ \\
\hline \multicolumn{5}{|l|}{ Household income (inter-quartile) } \\
\hline Lower $25 \%$ & $83.5(1.4)$ & $16.5(1.4)$ & 1 & 1 \\
\hline Lower 25\%-upper 25\% & $81.1(1.5)$ & $18.9(1.5)$ & $1.2(0.9-1.6)$ & $1.0(0.7-1.4)$ \\
\hline Upper $25 \%$ & $71.3(4.5)$ & $28.7(4.5)$ & $2.0(1.3-3.3)$ & $1.4(0.9-2.1)$ \\
\hline \multicolumn{5}{|l|}{ Physical activity } \\
\hline Low & $81.4(1.2)$ & $18.6(1.2)$ & 1 & 1 \\
\hline Moderate exercise $\geq$ once per week & $80.5(2.1)$ & $19.5(2.1)$ & $1.1(0.8-1.4)$ & $1.0(0.8-1.4)$ \\
\hline \multicolumn{5}{|l|}{ Body mass index $x^{\S}$} \\
\hline$<18.5$ & $88(3)$ & $12.0(3.0)$ & 1 & 1 \\
\hline $18.5-22.9$ & $79.9(1.8)$ & $20.1(1.8)$ & $1.9(1.0-3.3)$ & $1.2(0.6-2.2)$ \\
\hline $23.0-24.9$ & $79.3(2.1)$ & $20.7(2.1)$ & $1.9(1.1-3.4)$ & $1.2(0.6-2.4)$ \\
\hline$>25.0$ & $83(1.6)$ & $17.0(1.6)$ & $1.5(0.8-2.8)$ & $0.9(0.4-2.0)$ \\
\hline \multicolumn{5}{|l|}{ Cigarette smoking } \\
\hline Current smoker & $85.9(2.1)$ & $14.1(2.1)$ & 1 & 1 \\
\hline Ex-smoker & $81(1.9)$ & $19.0(1.9)$ & $1.4(1.0-2.1)$ & $1.2(0.8-1.9)$ \\
\hline Nonsmoker & $79.9(1.3)$ & $20.1(1.3)$ & $1.5(1.1-2.2)$ & $1.0(0.7-1.6)$ \\
\hline \multicolumn{5}{|l|}{ Coffee drinking } \\
\hline None, monthly & $80.7(1.8)$ & $19.3(1.8)$ & 1 & 1 \\
\hline Weekly & $79.9(2.4)$ & $20.1(2.4)$ & $1.1(0.7-1.5)$ & $1.0(0.7-1.5)$ \\
\hline Daily & $81.4(1.5)$ & $18.6(1.5)$ & $1.0(0.7-1.3)$ & $0.9(0.6-1.1)$ \\
\hline \multicolumn{5}{|l|}{ Tea drinking } \\
\hline None, monthly & $82.9(1.2)$ & $17.1(1.2)$ & 1 & 1 \\
\hline Weekly & $73.9(2.6)$ & $26.1(2.6)$ & $1.7(1.3-2.3)$ & $1.3(0.9-1.9)$ \\
\hline Daily & $73.9(4.4)$ & $26.1(4.4)$ & $1.7(1.1-2.7)$ & $1.4(0.8-2.2)$ \\
\hline \multicolumn{5}{|l|}{ Alcohol drinking } \\
\hline None, <once a month & $81.5(1.2)$ & $18.5(1.2)$ & 1 & 1 \\
\hline $1-4$ times monthly & $79.5(2.5)$ & $20.5(2.5)$ & $1.1(0.8-1.6)$ & $1.0(0.7-1.5)$ \\
\hline 2-3 times weekly & $80(3.6)$ & $20.0(3.6)$ & $1.1(0.7-1.7)$ & $1.0(0.6-1.7)$ \\
\hline$\geq 4$ times weekly & $81.7(3.1)$ & $18.3(3.1)$ & $1.0(0.7-1.5)$ & $1.3(0.8-2.0)$ \\
\hline \multicolumn{5}{|c|}{ Skipped at least one meal in the previous two days } \\
\hline No & $80.9(1.3)$ & $19.1(1.3)$ & 1 & 1 \\
\hline Yes & $82.6(2.4)$ & $17.4(2.4)$ & $0.9(0.6-1.3)$ & $1.1(0.7-1.6)$ \\
\hline \multicolumn{5}{|l|}{ Perceived health status } \\
\hline Good & $80.5(1.8)$ & $19.5(1.8)$ & 1 & 1 \\
\hline Moderate & $78.4(1.9)$ & $21.6(1.9)$ & $1.1(0.8-1.5)$ & $1.2(0.8-1.7)$ \\
\hline $\mathrm{Bad}$ & $83.2(1.5)$ & $16.8(1.5)$ & $0.8(0.6-1.1)$ & $0.9(0.7-1.2)$ \\
\hline Health check-ups & & & & \\
\hline No & $79(1.7)$ & $21.0(1.7)$ & 1 & 1 \\
\hline Yes & $83.6(1.3)$ & $16.4(1.3)$ & $0.7(0.6-1.0)$ & $0.8(0.6-1.1)$ \\
\hline Influenza vaccination & & & & \\
\hline No & $80.1(1.4)$ & $19.9(1.4)$ & 1 & 1 \\
\hline Yes & $84.3(1.8)$ & $15.7(1.8)$ & $0.7(0.5-1.0)$ & $0.8(0.6-1.1)$ \\
\hline
\end{tabular}

*By logistic regression model. ${ }^{\dagger}$ Adjusted for all other characteristics included in the table. ${ }^{*}$ Education level: low, middle school graduate or below; middle, high school graduate; high, college graduate or above. ${ }^{\S}$ Calculated as weight in kilograms divided by height in meters squared. 
Table 3. Participant medical conditions

\begin{tabular}{|c|c|c|c|c|}
\hline \multirow{2}{*}{ Medical conditions } & \multicolumn{2}{|c|}{ \% (Standard error) } & \multicolumn{2}{|c|}{$95 \%$ confidence interval } \\
\hline & Vitamin-mineral nonusers & Vitamin-mineral users & Unadjusted odds ratio* & Adjusted $^{\dagger}$ odds ratio* \\
\hline \multicolumn{5}{|l|}{ Dyslipidemia } \\
\hline No & $82.3(1.3)$ & $17.7(1.3)$ & 1 & 1 \\
\hline Yes & $80.0(1.5)$ & $20.0(1.5)$ & $1.2(0.9-1.4)$ & $1.2(0.9-1.4)$ \\
\hline \multicolumn{5}{|l|}{ Diabetes mellitus } \\
\hline No & $82.0(1.2)$ & $18.0(1.2)$ & 1 & 1 \\
\hline Yes & $77.9(2.1)$ & $22.1(2.1)$ & $1.3(1.0-1.7)$ & $1.3(1.0-1.8)$ \\
\hline \multicolumn{5}{|c|}{ Cardiovascular diseases, coronary heart disease } \\
\hline No & $80.7(1.2)$ & $19.3(1.2)$ & 1 & 1 \\
\hline Yes & $84.4(2.2)$ & $15.6(2.2)$ & $0.8(0.5-1.1)$ & $0.8(0.5-1.1)$ \\
\hline \multicolumn{5}{|l|}{ Abdominal obesity ${ }^{\ddagger}$} \\
\hline No & $80.0(1.5)$ & $20.0(1.5)$ & 1 & 1 \\
\hline Yes & $82.9(1.4)$ & $17.1(1.4)$ & $0.8(0.6-1.1)$ & $0.8(0.6-1.0)$ \\
\hline \multicolumn{5}{|l|}{ Hypertension } \\
\hline No & $82.2(1.5)$ & $17.8(1.5)$ & 1 & 1 \\
\hline Yes & $80.4(1.3)$ & $19.6(1.3)$ & $1.1(0.9-1.4)$ & $1.2(0.9-1.5)$ \\
\hline \multicolumn{5}{|l|}{ Cancer } \\
\hline No & $81.1(1.1)$ & $18.9(1.1)$ & 1 & 1 \\
\hline Yes $(n=32)$ & $82.0(4.5)$ & $18.0(4.5)$ & $0.9(0.5-1.7)$ & $0.9(0.5-1.7)$ \\
\hline \multicolumn{5}{|l|}{ Osteoporosis } \\
\hline No & $81.8(1.2)$ & $18.2(1.2)$ & 1 & 1 \\
\hline Yes & $78.1(2.1)$ & $21.9(2.1)$ & $1.3(1.0-1.6)$ & $1.3(1.0-1.6)$ \\
\hline
\end{tabular}

*Logistic regression model. ${ }^{\dagger}$ Adjusted for all other characteristics including demographic and lifestyle characteristics, health behaviors, medical conditions (all characteristics included in Tables 2 and 3). ${ }^{\ddagger}$ Abdominal obesity: waist circumference in men $\geq 90 \mathrm{~cm}$, women $\geq 85 \mathrm{~cm}$.

Table 4. Participant food nutrient intakes (not included supplement intake) according to EAR recommendations*

\begin{tabular}{|c|c|c|c|c|c|c|c|c|}
\hline \multirow[b]{2}{*}{ Nutrient } & \multirow[b]{2}{*}{ EAR } & \multicolumn{3}{|c|}{ Men } & \multirow[b]{2}{*}{ EAR } & \multicolumn{3}{|c|}{ Women } \\
\hline & & $\begin{array}{l}\text { Vitamin-mineral } \\
\text { supplement nonusers } \\
\text { below EAR }\end{array}$ & $\begin{array}{l}\text { Vitamin-mineral } \\
\text { supplement users } \\
\text { below EAR }\end{array}$ & P-value & & $\begin{array}{l}\text { Vitamin-mineral } \\
\text { supplement nonusers } \\
\text { below EAR }\end{array}$ & $\begin{array}{l}\text { Vitamin-mineral } \\
\text { supplement users } \\
\text { below EAR }\end{array}$ & P-value \\
\hline Vitamin A & $625 \mu \mathrm{g} / \mathrm{d}$ & $86.1(1.5)$ & $13.9(1.5)$ & 0.003 & $500 \mu \mathrm{g} / \mathrm{d}$ & $82.8(1.4)$ & $17.2(1.4)$ & $<0.001$ \\
\hline Vitamin C & $75 \mathrm{mg} / \mathrm{d}$ & $87.8(1.5)$ & $12.2(1.5)$ & $<0.001$ & 60 mg/d & $82.7(1.5)$ & $17.3(1.5)$ & 0.007 \\
\hline Thiamine & $1.0 \mathrm{mg} / \mathrm{d}$ & $86.5(1.6)$ & $13.5(1.6)$ & 0.003 & $0.9 \mathrm{mg} / \mathrm{d}$ & $81.9(1.4)$ & $18.1(1.4)$ & 0.009 \\
\hline Riboflavin & $1.1 \mathrm{mg} / \mathrm{d}$ & $86.7(1.3)$ & $13.3(1.3)$ & $<0.001$ & $0.9 \mathrm{mg} / \mathrm{d}$ & $81.9(1.3)$ & $18.1(1.3)$ & 0.002 \\
\hline Niacin & 12 mg/d & $85.9(1.7)$ & $14.1(1.7)$ & 0.038 & $11 \mathrm{mg} / \mathrm{d}$ & $81.7(1.5)$ & $18.3(1.5)$ & 0.031 \\
\hline Calcium & $\begin{array}{c}800 \mathrm{mg} / \mathrm{d}(65-70 \mathrm{y}) \\
1,000 \mathrm{mg} / \mathrm{d}(>70 \mathrm{y})\end{array}$ & $84.7(1.3)$ & $15.3(1.3)$ & $<0.001$ & $1,000 \mathrm{mg} / \mathrm{d}$ & $79.9(1.3)$ & 20.1 (1.3) & $<0.001$ \\
\hline Iron & $6 \mathrm{mg} / \mathrm{d}$ & $86.3(2.8)$ & $13.7(2.8)$ & 0.255 & $5 \mathrm{mg} / \mathrm{d}$ & $86.9(2.0)$ & $13.1(2.0)$ & $<0.001$ \\
\hline Phosphorus & $580 \mathrm{mg} / \mathrm{d}$ & $83.2(4.1)$ & $16.8(4.1)$ & 0.976 & $580 \mathrm{mg} / \mathrm{d}$ & $83.8(2.2)$ & $16.2(2.2)$ & 0.044 \\
\hline
\end{tabular}

Values are presented as \% (standard error).

EAR, estimated average requirement.

*Data were collected by 24-hour recall.

A previous study using KNHANES data from Korean adults (20 years of age and older) reported that vitamin-mineral supplement use was associated with older age and higher household income, ${ }^{10)}$ but the current study did not observe a similar association. However, our findings were in agreement with another study of Korean elderly. Song and $\mathrm{Kim}^{13)}$ assessed patterns of vitamin-mineral supplement use by the elderly in Korea. Vitamin-mineral users were more likely to be female, live in the city, be more educated, and have higher household incomes compared with nonusers.

The vitamin-mineral supplement users did not have any association to medical conditions. Lee and $\mathrm{Kim}^{10)}$ reported that participants with bone disease more commonly reported vitamin supplementation. Similarly, the Physicians' Health Study cohort study in the US found that men with history of hypercholesterolemia, cancer, and hypertension were more likely to use multivitamins. ${ }^{9)}$

The differences in findings between our study and previous studies are probably because our study focused on the elderly population. During the same period (2007-2009), the KNHANES reported that dietary supplement use was higher in middle-aged than in older adult Koreans. ${ }^{12)}$ However, in the US, multivitamin use was more common in older people than among those of middle age. ${ }^{17)}$ This result suggests that vitamin-mineral supplementation is less prevalent among the el- 
derly in Korea, which may partially explain the lack of association between vitamin-mineral use and medical conditions. However, the link between vitamin-mineral supplement use and medical conditions requires further research.

Health behaviors, regular diet behavior, self-reported health status, regular health check-up, and influenza vaccination were not related to use of vitamin-mineral supplements. According to the 1999-2000 US National health and nutrition examination survey (NHANES), the use of dietary supplements was higher among those who perceived their health status as good. ${ }^{2)}$ In contrast, data from the European Prospective Investigation into Cancer and Nutrition and other studies in Germany, the Netherlands, Sweden, and Denmark showed higher use of dietary supplements in those who perceived their health status as moderate or poor. ${ }^{3,18,19)}$ One might hypothesize that people in the US use dietary supplements to prevent diseases, whereas people in Europe use dietary supplements to treat diseases. ${ }^{20)}$ According to a previous study of Korean elderly, the most commonly reported reasons for using vitamin-mineral supplements were to stay healthy (37.6\%) and to relieve fatigue (22.3\%), suggesting that use of dietary supplements among the elderly in Korea as a preventive measure. ${ }^{13)}$

In both men and women intake of all nutrients assessed in this study (vitamin A, vitamin C, thiamine, riboflavin, niacin, calcium, iron, and phosphorus) from food sources alone were significantly higher in vitamin-mineral supplement users. These results are consistent with those of previous studies reporting that dietary supplement users consumed more nutritious diets than nonusers. ${ }^{2,12,17,19,21)}$ Pouchieu et al. ${ }^{22)}$ examined daily food intakes among dietary supplement users and non-users, observing healthier diets overall among dietary supplement users compared to nonusers-they ate more vegetables, fruits, wholegrain foods, fish/seafood, and ate less poultry, processed meat, cakes/biscuits/pastries, and snacks/pizzas and drank fewer alcoholic beverages. In addition, according to the 2007-2008 NHANES in the US, a large number of participants taking dietary supplements satisfied EAR from food sources alone, without use of dietary supplements. ${ }^{17)}$ These results are consist with previous studies reporting that vitaminmineral supplement users had overall healthier profiles.

This study has some limitations. First, the KNHANES data were based on a cross-sectional study design; thus, the current study could only suggest associations, rather than causality. Second, vitamin-mineral supplement use and medical conditions were assessed by self-reported data, which are subject to recall bias. Finally, the ratio of participants with nutrient intakes below the EAR from food sources alone was calculated using the one-day, 24-hour recall method, which might not reflect usual dietary habits.

However, the strength of this study is its use of data from the KNHANES, a nationally representative survey, which increases the reliability of the results. To our knowledge, this is the first study to use KNHANES data to analyze vitamin-mineral supplementation among the elderly in Korea.

In conclusion, highly educated person, elderly women in Korea had a greater likelihood of using vitamin-mineral supplements. In addi- tion, the ratio of nutrient intake from food sources alone was higher among vitamin-mineral supplement users than nonusers. The results of our study suggest that vitamin-mineral supplement use may be an indicator of healthier diet in the elderly; however, this observation requires further validation. Health professionals should routinely determine supplement use history and provide patients with specific information.

\section{CONFLICT OF INTEREST}

No potential conflict of interest relevant to this article was reported.

\section{REFERENCES}

1. Park HA. Top 10 dietary supplements of Korean adults from the 4th Korea National Health and Nutrition Examination Survey. Korean J Fam Med 2011;32:263-6.

2. Radimer K, Bindewald B, Hughes J, Ervin B, Swanson C, Picciano MF. Dietary supplement use by US adults: data from the National Health and Nutrition Examination Survey, 1999-2000. Am J Epidemiol 2004; 160:339-49.

3. Skeie G, Braaten T, Hjartaker A, Lentjes M, Amiano P, Jakszyn P, et al. Use of dietary supplements in the European Prospective Investigation into Cancer and Nutrition calibration study. Eur J Clin Nutr 2009;63 Suppl 4:S226-38.

4. Bailey RL, Gahche JJ, Lentino CV, Dwyer JT, Engel JS, Thomas PR, et al. Dietary supplement use in the United States, 2003-2006. J Nutr 2011;141:261-6.

5. Rautiainen S, Akesson A, Levitan EB, Morgenstern R, Mittleman MA, Wolk A. Multivitamin use and the risk of myocardial infarction: a population-based cohort of Swedish women. Am J Clin Nutr 2010;92:1251-6.

6. Akbar S, Bellary S, Griffiths HR. Dietary antioxidant interventions in type 2 diabetes patients: a meta-analysis. Br J Diabetes Vasc Dis 2011; 11:62-8.

7. Heine-Broring RC, Winkels RM, Renkema JM, Kragt L, van Orten-Luiten AC, Tigchelaar EF, et al. Dietary supplement use and colorectal cancer risk: a systematic review and meta-analyses of prospective cohort studies. Int J Cancer 2015;136:2388-401.

8. Gaziano JM, Sesso HD, Christen WG, Bubes V, Smith JP, MacFadyen J, et al. Multivitamins in the prevention of cancer in men: the Physicians' Health Study II randomized controlled trial. JAMA 2012;308:1871-80.

9. Rautiainen S, Wang L, Gaziano JM, Sesso HD. Who uses multivitamins?: a cross-sectional study in the Physicians' Health Study. Eur J Nutr 2014;53:1065-72.

10. Lee JS, Kim J. Factors affecting the use of dietary supplements by Korean adults: data from the Korean National Health and Nutrition Examination Survey III. J Am Diet Assoc 2009;109:1599-605.

11. Rock CL. Multivitamin-multimineral supplements: who uses them? Am J Clin Nutr 2007;85:277S-279S.

12. Kang M, Kim DW, Baek YJ, Moon SH, Jung HJ, Song YJ, et al. Dietary supplement use and its effect on nutrient intake in Korean adult population in the Korea National Health and Nutrition Examination Survey IV (2007-2009) data. Eur J Clin Nutr 2014;68:804-10.

13. Song B, Kim M. Patterns of vitamin-mineral supplement usage by the 
elderly in Korea. Korean J Nutr 1997;30:139-46.

14. Yoon JY, Park HA, Kang JH, Kim KW, Hur YI, Park JJ, et al. Prevalence of dietary supplement use in Korean children and adolescents: insights from Korea National Health and Nutrition Examination Survey 2007-2009. J Korean Med Sci 2012;27:512-7.

15. Korea Centers for Disease Control and Prevention. The third Korea National Health and Nutrition Examination Survey (KNHANES IV), 2008, 2009. Cheongju: Korea Centers for Disease Control and Prevention; 2009.

16. Lee SY, Park HS, Kim DJ, Han JH, Kim SM, Cho GJ, et al. Appropriate waist circumference cutoff points for central obesity in Korean adults. Diabetes Res Clin Pract 2007;75:72-80.

17. Kennedy ET, Luo H, Houser RF. Dietary supplement use pattern of U.S. adult population in the 2007-2008 National Health and Nutrition Examination Survey (NHANES). Ecol Food Nutr 2013;52:76-84.

18. Messerer M, Johansson SE, Wolk A. Sociodemographic and health be- havior factors among dietary supplement and natural remedy users. Eur J Clin Nutr 2001;55:1104-10.

19. Knudsen VK, Rasmussen LB, Haraldsdottir J, Ovesen L, Bulow I, Knudsen N, et al. Use of dietary supplements in Denmark is associated with health and former smoking. Public Health Nutr 2002;5:463-8.

20. Rovira MA, Grau M, Castaner O, Covas MI, Schroder H; REGICOR Investigators. Dietary supplement use and health-related behaviors in a Mediterranean population. J Nutr Educ Behav 2013;45:386-91.

21. Sebastian RS, Cleveland LE, Goldman JD, Moshfegh AJ. Older adults who use vitamin/mineral supplements differ from nonusers in nutrient intake adequacy and dietary attitudes. J Am Diet Assoc 2007;107: 1322-32.

22. Pouchieu C, Andreeva VA, Peneau S, Kesse-Guyot E, Lassale C, Hercberg S, et al. Sociodemographic, lifestyle and dietary correlates of dietary supplement use in a large sample of French adults: results from the NutriNet-Sante cohort study. Br J Nutr 2013;110:1480-91. 